\title{
Persistence of innovation in Dutch manufacturing : is it spurious?
}

Citation for published version (APA):

Raymond, W., Mohnen, P., Palm, F. C., \& Schim van der Loeff, S. (2006). Persistence of innovation in Dutch manufacturing : is it spurious? METEOR, Maastricht University School of Business and Economics. METEOR Research Memorandum No. 009 https://doi.org/10.26481/umamet.2006009

Document status and date:

Published: 01/01/2006

DOI:

10.26481/umamet.2006009

Document Version:

Publisher's PDF, also known as Version of record

\section{Please check the document version of this publication:}

- A submitted manuscript is the version of the article upon submission and before peer-review. There can be important differences between the submitted version and the official published version of record.

People interested in the research are advised to contact the author for the final version of the publication, or visit the DOI to the publisher's website.

- The final author version and the galley proof are versions of the publication after peer review.

- The final published version features the final layout of the paper including the volume, issue and page numbers.

Link to publication

\footnotetext{
General rights rights.

- You may freely distribute the URL identifying the publication in the public portal. please follow below link for the End User Agreement:

www.umlib.nl/taverne-license

Take down policy

If you believe that this document breaches copyright please contact us at:

repository@maastrichtuniversity.nl

providing details and we will investigate your claim.
}

Copyright and moral rights for the publications made accessible in the public portal are retained by the authors and/or other copyright owners and it is a condition of accessing publications that users recognise and abide by the legal requirements associated with these

- Users may download and print one copy of any publication from the public portal for the purpose of private study or research.

- You may not further distribute the material or use it for any profit-making activity or commercial gain

If the publication is distributed under the terms of Article $25 \mathrm{fa}$ of the Dutch Copyright Act, indicated by the "Taverne" license above, 


\title{
Persistence of Innovation in Dutch Manufacturing: Is it
}

\section{Spurious?*}

\author{
Wladimir Raymond†, Pierre Mohnen $\ddagger$ Franz Palm ${ }^{\S}$ and Sybrand Schim van der Loeff ฯ
}

February 20, 2006

\begin{abstract}
This paper studies the persistence of innovation and the dynamics of innovation output in Dutch manufacturing using firm data from three waves of the Community Innovation Surveys (CIS), pertaining to the periods 1994-1996, 1996-1998, and 19982000. We estimate by maximum likelihood a dynamic panel data type 2 tobit model accounting for individual effects and handling the initial conditions problem. We find that there is no evidence of true persistence in achieving technological product or process innovations, while past shares of innovative sales condition, albeit to a small extent, current shares of innovative sales.
\end{abstract}

Keywords: Dynamic panel data type 2 tobit, Innovation, Spurious persistence.

JEL classification: C33, C34, O31

${ }^{*}$ Acknowledgements: The empirical part of this study has been carried out at the Centre for Research of Economic Microdata at Statistics Netherlands. The authors wish to thank Statistics Netherlands, and in particular Bert Diederen, for helping us in accessing and using the Micronoom data set. The views expressed in this paper are solely those of the authors. The authors also wish to thank François Laisney for his helpful comments. The first author acknowledges financial support from METEOR.

\footnotetext{
${ }^{\dagger}$ University of Maastricht, W.Raymond@KE.unimaas.nl

${ }^{\ddagger}$ University of Maastricht, MERIT and CIRANO, MERIT, University of Maastricht, P.O. Box 6166200 MD Maastricht, The Netherlands; Tel: +31 43388 3869; Fax: + 3143388 4905; P.Mohnen@MERIT.unimaas.nl

$\S$ University of Maastricht and CESifo fellow, F.Palm@KE.unimaas.nl

๑University of Maastricht, S.Loeff@KE.unimaas.nl
} 


\section{Introduction}

This paper examines, at the firm level, the dynamics of the innovation process in Dutch manufacturing using three waves of the Community Innovation Survey (henceforth CIS) pertaining to the periods 1994-1996, 1996-1998 and 1998-2000. More specifically, we attempt to answer two questions. First, does being successful in past innovation activities increase the probability of being successful in current innovation activities? Secondly, does past innovation output, as measured by the share in total sales of innovative sales, ${ }^{1}$ generate current innovation output?

The first research question relates to the literature on the persistence of innovation which, at the micro level, plays an important role in the context of endogenous growth models (Romer, 1990; Aghion and Howitt, 1992). It also helps to understand industrial economics phenomena such as the persistence of profitability (Roberts, 2001) and total factor productivity (TFP) growth (Geroski, 1989). Several theoretical explanations of the persistence of innovation (at the firm level) exist in the literature. In one approach the persistence of innovation is explained by the existence of sunk costs: in order to build and maintain an $R \& D$ department, $R \& D$ expenditures are regular. In the linear model of innovation as opposed to the chain-link model a direct relationship between a firm's R\&D expenditures and its innovations is postulated such that the persistence of innovation coincides with that of R\&D expenditures. A second explanation of the persistence of innovation pertains to the financial constraints that a firm may face in funding R\&D activities, which makes it dependent on retained earnings as a source of funds. Innovations that have met a commercial success in the past generate profits that may be invested in current innovation activities and hence "success breeds success". Finally an explanation of the persistence of innovation is given by the learning-by-doing model. It predicts that the production of innovations is subject to dynamic economies of scale. In other words, knowledge that has been used to produce past innovations can,

\footnotetext{
${ }^{1}$ This study considers products that are new to the firm, not necessarily new to the market.
} 
assuming that the depreciation rate of innovative abilities is small, be used to produce current and even future innovations. In Schumpeterian terms, the three theoretical explanations of the persistence of innovation can be labeled as "creative accumulation", as opposed to "creative destruction", where the latter term is used to explain the absence of persistence in innovation activities.

The dynamics of innovation output, investigated by the second research question, plays a crucial role in understanding the dynamics of firms' technological performance (e.g. innovative sales) and economic performance (e.g. profits). Since the empirical work by Crépon et al. (1998), a great number of empirical studies focus on the relationship between innovation output and firm performance, the latter variable being measured, for instance, by sales per employee, value-added per employee, export per employee, growth rates of sales, total employment growth and so on. The main finding of these studies is that, regardless of how performance is measured, innovation output positively and significantly affects firm performance, with the exception of the study by Klomp and van Leeuwen (2001) that finds a negative but insignificant effect of innovation output on employment growth. ${ }^{2}$ For instance, innovation output has a positive and significant effect on value-added per employee of French firms (Crépon et al., 1998), sales per employee of German firms (Janz et al., 2003), sales growth of Dutch firms (Klomp and van Leeuwen, 2001), and labor productivity (value-added per employee) growth of Swedish firms (Lööf and Heshmati, 2002a). Lööf and Heshmati (2002b) perform a sensitivity analysis using, besides the previously-mentioned ones, three additional measures of firm performance, namely, sales margin, profit before and after depreciation (in level and growth rates), and find the same pattern of positive and significant effect of innovation output on firm performance. Because of this close relationship between innovation output and firm performance, the dynamics of the former is expected to explain that of the latter. In

\footnotetext{
${ }^{2}$ The relationship between innovation and employment is not a clear-cut one. Empirical studies identify both a positive and a negative effect of the former on the latter. The sign of the relationship depends, e.g., on the type of the data, the time-period and the level of analysis (firm versus industry level) (Pianta, 2004).
} 
other words, our second research question can help us address the issue of the persistence of firm performance (Cefis, 2003b; Cefis and Ciccarelli, 2005).

This study contributes to the empirical literature on innovation in a number of ways. Firstly, it analyzes persistence using other output measures than patents. Secondly, unlike the aforementioned empirical studies on firm performance, three waves of the CIS, pertaining to the Dutch manufacturing sector, are used for the first time to link the persistence of innovation (qualitative) to the dynamics of firms' technological performance (quantitative). We estimate a dynamic panel data type 2 tobit model accounting for unobserved individual effects and handling the initial conditions problem encountered when estimating dynamic panel data models. The incidence and the intensity of innovation are jointly estimated allowing for a correlation between the processes governing the introduction of new or significantly improved products and/or processes, and the generation of innovative sales. We use estimation techniques suggested by Wooldridge (2005), and generalized in Raymond et al. (2005), and find that being successful in past innovation activities does not increase the probability of being successful in current innovation activities, and that past innovation output does condition, albeit to a small extent, current innovation output.

Section 2 summarizes the findings of the empirical literature on the persistence of innovation and firm performance. Section 3 presents the model that is estimated in Section 4. We describe the data used to implement the model in Section 5, present and discuss estimation results in Section 6, and conclude in Section 7.

\section{Literature}

This section summarizes the findings of the empirical literature on the persistence of innovation. Two types of studies are identified according to whether patent or other data are used (Table 1). We explain the importance of the type of data that are used 
to measure innovation activities when persistence is analyzed. We also describe the findings of the rather few empirical studies on the relationship between the persistence of innovation output and that of firm performance.

\subsection{The persistence of innovation}

The studies on the persistence of innovation are motivated by testing the Schumpeter Mark I and II hypotheses. In other words, authors seek to know whether innovation activities are subject to "creative destruction" or "creative accumulation". The hypothesis of whether innovation activities are subject to "dynamic economies of scales" is also tested in these studies. Finally, industry and country differences in the persistence of innovation are investigated.

\subsubsection{Patent data}

Innovation activities are captured in these studies by the number of patents that are either applied for or granted by the European Patent office (henceforth EPO) and the United States Patents and Trademarks Office (henceforth US PTO). Table 1 shows that, with the exception of Crépon and Duguet (1997), all the studies on the persistence of innovation that use patent data conclude more or less alike regardless of the methodology: there is no clear-cut evidence of strong persistence in innovation activities. In fact, those studies share a common drawback, namely, the type of data used to analyze persistence. The limitations of patent data are well-known (Griliches, 1990), and the inability to obtain unequivocal empirical results using such data is therefore not surprising. Indeed, in order for a firm to be properly accounted for in a patent data set, it has to be the first to apply for a patent. Hence, when analyzing the persistence of innovation using patent data, one is unwittingly analyzing the persistence of "winning the patent race", which is unlikely to be strong (Duguet and Monjon, 2002). As a result, other types of data should be used to investigate the persistence of innovation activities. 


\subsubsection{Major innovation, $R \& D$ and CIS data}

Major innovation, R\&D and CIS data are also used to analyze the persistence of innovation activities. The first type of data yields results that are similar to those of studies using patent data. Duguet and Monjon (2002) point out that persistence is also likely to be low when using major innovation data. Indeed, since a major innovation is one that meets a commercial success, innovators are likely to be innovation or commercial leaders, which is unlikely to persist over a long period of time. Thus, major innovation data are as demanding as patent data when analyzing the persistence of innovation. On the other hand, R\&D and CIS data are seen as less demanding as persistence can be analyzed at the firm level without mentioning the patenting or market leadership status of the firm. In this case, regardless of the methodology, persistence in innovation activities is found to be high, whether input measures (Castillejo et al., 2004; Peters, 2005) or output measures (Duguet and Monjon, 2002) of innovation are used.

\subsection{The persistence of innovation output and firm performance}

All the empirical studies mentioned in Section 1 on the relationship between innovation output and firm performance are cross-sectional, whereas this one is based on panel data. ${ }^{3}$ Hence, they cannot analyze the dynamics of the innovation process and that of firm performance. Little is known about the relationship between the dynamics of innovation and that of firm performance. Two instances of studies that investigate this relationship are Cefis (2003b) and Cefis and Ciccarelli (2005). Both studies use patent data and find that persistent innovators have profits that are and remain higher than those of non-persistent innovators, hence the persistence of innovation and that of firm performance are closely related to each other.

\footnotetext{
${ }^{3}$ To the best of our knowledge, van Leeuwen's (2002) study is the only one that analyzes the dynamics of innovation input (R\&D expenditures/total sales) and output (innovative sales/total sales), and links innovation output to firm performance. However, his analysis is not done in a "true" panel data framework in that individual effects are not accounted for.
} 
Our study attempts to give a first insight into the dynamics of the innovation process in Dutch manufacturing using three waves of the CIS. We consider a model of innovative behavior in a "true" dynamic panel data framework, i.e. accounting for unobserved individual effects and handling the initial conditions problem. We estimate a dynamic panel data type 2 tobit model, according to Amemiya's (1984) terminology, which encompasses the cross-sectional type 2 tobit model studied by, for instance, Brouwer and Kleinknecht (1996) and Mairesse and Mohnen (2001). The model is described as follows.

\section{Econometric model}

The model explains the achievement by Dutch manufacturing enterprises of technological product and/or process (TPP) innovations and the impact of these innovations on the share of innovative sales. Formally, it is written as

$$
\begin{aligned}
& d_{i t}=1\left[\rho d_{i, t-1}+\delta^{\prime} \mathbf{w}_{i t}+\eta_{i}+u_{i t}>0\right] \\
& y_{i t}= \begin{cases}\gamma y_{i, t-1}+\beta^{\prime} \mathbf{x}_{i t}+\alpha_{i}+\varepsilon_{i t} & \text { if } d_{i t}=1 \\
0 & \text { if } d_{i t}=0,\end{cases}
\end{aligned}
$$

with $t=1, \ldots T ; i=1, \ldots N$.

Equation (1) models the current decision of enterprise $i$ to innovate as a latent function of its past innovation achievement $\left(d_{i, t-1}\right)$, its observable characteristics $\left(\mathbf{w}_{i t}\right)^{4}$, time-invariant unobserved individual effects $\left(\eta_{i}\right)$ and other time-variant unobserved variables $\left(u_{i t}\right)$ uncorrelated with $\mathbf{w}_{i t}$. The expression in square brackets represents the incentive to innovate. If the incentive is sufficiently high, enterprise $i$ is a TPP innovator in which case $d_{i t}$ is observed to be 1 . The scalar $\rho$ and the vector $\delta^{\prime}$ capture respectively the effects of past innovation achievement and firm characteristics on current innovation achievement, and are to be estimated. A positive and statistically significant estimate

\footnotetext{
${ }^{4} \mathbf{w}_{i t}$ could also include market specific characteristics if they were observable.
} 
of $\rho$ identifies the presence of persistence in innovation which may occur for two reasons, because of state dependence or because of unobserved effects or left-out variables that are correlated over time (through serially-correlated errors or individual effects). Heckman (1981a; 1981c) refers to the first phenomenon as true state dependence and the second one as spurious state dependence. True state dependence states that past innovation achievement increases positively and significantly the probability of current innovation achievement (true persistence). ${ }^{5}$ In order to distinguish it from spurious state dependence, unobserved effects that are correlated over time and the initial conditions must be properly accounted for when estimating eq. (1).

Equation (2) models the current share of innovative sales $\left(y_{i t}\right)$ of innovator $i\left(d_{i t}=1\right)$ as being determined by its past share of innovative sales $\left(y_{i, t-1}\right)$, its characteristics $\left(\mathbf{x}_{i t}\right)$, time-invariant unobserved individual effects $\left(\alpha_{i}\right)$ and other time-variant unobserved variables $\left(\varepsilon_{i t}\right)$ uncorrelated with $\mathbf{x}_{i t}$. This share is zero if enterprise $i$ is not an innovator, and the full set of regressors included into $\mathbf{x}_{i t}$ are only available when enterprise $i$ is an innovator. The scalar $\gamma$ and the vector $\beta^{\prime}$ capture respectively the effects of past share of innovative sales and firm characteristics on current share of innovative sales, and are to be estimated.

Equations (1) and (2) are jointly estimated allowing for a correlation between the processes governing the introduction of TPP innovations and the generation of innovative sales. We now turn to the estimation technique.

\section{Maximum likelihood estimation}

This section explains how to estimate the dynamic panel data type 2 tobit model accounting for individual effects and handling the initial conditions problem. It is shown in the econometric literature that the coefficient associated with the lagged dependent

\footnotetext{
${ }^{5}$ When the term persistence is used in this study without any further explanation, it is to be understood as true persistence which occurs in the case of true state dependence.
} 
variable can be overestimated if these two problems are not properly accounted for. Estimation techniques that properly handle these problems are known in the econometric literature (Heckman, 1981b; Wooldridge, 2005).

Kyriazidou (2001) suggests a "semi-parametric fixed-effects" approach, i.e. the individual effects $\eta_{i}$ and $\alpha_{i}$ are assumed to be fixed, and derives moment restrictions (along the lines of Ahn and Schmidt (1995)) that are exploited to construct two-step GMM-type estimators. In the first step, the parameters of eq. (1) are consistently estimated, e.g., by methods suggested by Honoré and Kyriazidou (2000). In the second step, these estimates are used to construct kernel weights that are larger for individuals whose sample selection effect is small. Under appropriate assumptions, the derived kernel-weighted GMM estimators are shown to be consistent and asymptotically normal. These estimators, however, cannot be applied in this study because of data limitations. First, the fixed-effects approach requires data that show a lot of variation over time (within variation), otherwise they are wiped out when time-differencing. This is hardly the case in our data since most of the variables are qualitative, and the continuous ones exhibit little within variation. For instance, the approach does not identify the effects of industry dummies which are assumed to capture technological opportunities. Secondly, the estimators are effective when the number of time periods is fairly large $(T \geq 4)$, which is not the case in our study either. Indeed, the moment equations require time-differencing resulting in a loss of information in the data, and the remaining information must be sufficient to estimate the model, which is not feasible when $T$ is too small.

In order to cope with the limitations of our data, we consider an error-components approach and make distributional assumptions on the individual effects. We "integrate out" the individual effects and use the Wooldridge (2005) approach of handling the initial conditions problem. The estimator is described as follows. We assume the individual 
effects to be correlated with the initial conditions and the regressors, i.e.

$$
\eta_{i}=b_{0}^{s}+b_{1}^{s} d_{i 0}+\mathbf{b}_{2}^{\prime s} \mathbf{w}_{i}+a_{1 i}
$$

and

$$
\alpha_{i}=b_{0}^{r}+b_{1}^{r} y_{i 0}+\mathbf{b}_{2}^{\prime r} \mathbf{x}_{i}+a_{2 i}
$$

where $\mathbf{w}_{i}^{\prime}=\left(\mathbf{w}_{i 1}^{\prime}, \ldots, \mathbf{w}_{i T}^{\prime}\right), \mathbf{x}_{i}^{\prime}=\left(\mathbf{x}_{i 1}^{\prime}, \ldots, \mathbf{x}_{i T}^{\prime}\right)$, and $b_{0}^{s}, b_{1}^{s}, \mathbf{b}_{2}^{\prime s}, b_{0}^{r}, b_{1}^{r}$ and $\mathbf{b}_{2}^{\prime r}$ are to be estimated. ${ }^{6}$ The scalars $b_{1}^{s}$ and $b_{1}^{r}$ capture the dependence of the individual effects on the initial conditions. The vectors $\left(a_{1 i}, a_{2 i}\right)^{\prime}$ and $\left(u_{i t}, \epsilon_{i t}\right)^{\prime}$ are assumed to be independently and identically (over time and across individuals) normally distributed with means zero and covariance matrices $\Omega_{a_{1} a_{2}}=\left(\begin{array}{cc}\sigma_{a_{1}}^{2} & \rho_{a_{1} a_{2}} \sigma_{a_{1}} \sigma_{a_{2}} \\ \rho_{a_{1} a_{2}} \sigma_{a_{1}} \sigma_{a_{2}} & \sigma_{a_{2}}^{2}\end{array}\right)$ and $\Omega_{u \epsilon}=\left(\begin{array}{cc}1 & \rho_{u \epsilon} \sigma_{\epsilon} \\ \rho_{u \epsilon} \sigma_{\epsilon} & \sigma_{\epsilon}^{2}\end{array}\right)$ respectively, and independent of each other. The likelihood function of one individual, starting from $t=1$ and conditional on the regressors and the initial conditions, is written as

$$
L_{i}=\int_{-\infty}^{\infty} \int_{-\infty}^{\infty} \prod_{t=1}^{T} L_{i t}\left(y_{i t} \mid d_{i 0}, d_{i, t-1}, \mathbf{w}_{i}, y_{i 0}, y_{i, t-1}, \mathbf{x}_{i}, a_{1 i}, a_{2 i}\right) g\left(a_{1 i}, a_{2 i}\right) d a_{1 i} d a_{2 i}
$$

where $\prod_{t=1}^{T} L_{i t}\left(y_{i t} \mid d_{i 0}, d_{i, t-1}, \mathbf{w}_{i}, y_{i 0}, y_{i, t-1}, \mathbf{x}_{i}, a_{1 i}, a_{2 i}\right)$ and $g\left(a_{1 i}, a_{2 i}\right)$ denote respectively the likelihood function if the individual effects are treated as fixed, and the bivariate normal density function of $\left(a_{1 i}, a_{2 i}\right)^{\prime}$. Define

$$
A_{i t}=\rho d_{i, t-1}+\delta^{\prime} \mathbf{w}_{i t}+b_{0}^{s}+b_{1}^{s} d_{i 0}+\mathbf{b}_{2}^{\prime s} \mathbf{w}_{i}
$$

\footnotetext{
${ }^{6}$ The approach considered in equations (3) and (4) allows the individual effects to be correlated with the regressors. However, because of the lack of variation over time (within variation) in $\mathbf{w}_{i t}$ and $\mathbf{x}_{i t}$, a more restricted approach is considered in this analysis where the individual effects are assumed to be correlated only with the initial conditions.
} 
and

$$
B_{i t}=\gamma y_{i, t-1}+\beta^{\prime} \mathbf{x}_{i t}+b_{0}^{r}+b_{1}^{r} y_{i 0}+\mathbf{b}_{2}^{\prime r} \mathbf{x}_{i},
$$

the likelihood function under the fixed-effects assumption is written as

$$
\prod_{t=1}^{T} \Phi\left[-\left(A_{i t}+a_{1 i}\right)\right]^{\left(1-d_{i t}\right)}\left[\frac{1}{\sigma_{\epsilon}} \phi\left(\frac{y_{i t}-B_{i t}-a_{2 i}}{\sigma_{\epsilon}}\right) \Phi\left(\frac{A_{i t}+a_{1 i}+\frac{\rho_{u \epsilon}}{\sigma_{\epsilon}}\left(y_{i t}-B_{i t}-a_{2 i}\right)}{\sqrt{1-\rho_{u \epsilon}^{2}}}\right)\right]^{d_{i t}} .
$$

The double integral in equation (5) can be approximated by "two-step" Gauss-Hermite quadrature which states that

$$
\int_{-\infty}^{\infty} e^{-z^{2}} f(z) d z \simeq \sum_{m=1}^{M} w_{m} f\left(a_{m}\right)
$$

where $w_{m}$ and $a_{m}$ are respectively the weights and abscissas of the Gauss-Hermite integration, the tables of which are formulated in mathematical textbooks (e.g. Abramovitz and Stegun, 1964), and $M$ is the total number of integration points. The larger $M$, the more accurate the Gauss-Hermite approximation.

Equation (5) is written as

$$
L_{i}=\int_{-\infty}^{\infty} g\left(a_{2 i}\right) \prod_{t=1}^{T}\left[\frac{1}{\sigma_{\epsilon}} \phi\left(\frac{y_{i t}-B_{i t}-a_{2 i}}{\sigma_{\epsilon}}\right)\right]^{d_{i t}} H\left(a_{2 i}\right) d a_{2 i},
$$

where $H\left(a_{2 i}\right)$ is written as

$$
\int_{-\infty}^{\infty} g\left(a_{1 i} \mid a_{2 i}\right) \prod_{t=1}^{T} \Phi\left[-\left(A_{i t}+a_{1 i}\right)\right]^{\left(1-d_{i t}\right)}\left[\Phi\left(\frac{A_{i t}+a_{1 i}+\frac{\rho_{u \epsilon}}{\sigma_{\epsilon}}\left(y_{i t}-B_{i t}-a_{2 i}\right)}{\sqrt{1-\rho_{u \epsilon}^{2}}}\right)\right]^{d_{i t}} d a_{1 i}
$$

In the first step, we approximate equation (11) using eq. (9). In the second step, we replace the approximation into eq. (10) and apply again eq. (9). The final expression of the likelihood is written as 


$$
\begin{aligned}
& L_{i} \simeq \frac{\sqrt{1-\rho_{a_{1} a_{2}}^{2}}}{\pi} \sum_{p=1}^{P} w_{p}\left\{\prod_{t=1}^{T}\left[\frac{1}{\sigma_{\epsilon}} \phi\left(\frac{y_{i t}-B_{i t}-a_{p} \sigma_{a_{2}} \sqrt{2\left(1-\rho_{a_{1} a_{2}}^{2}\right)}}{\sigma_{\epsilon}}\right)\right]^{d_{i t}}\right. \\
& \times \sum_{m=1}^{M} w_{m}\left\{\exp \left[2 \rho_{a_{1} a_{2}}^{2} a_{p} a_{m}\right] \prod_{t=1}^{T} \Phi\left[-\left(A_{i t}+a_{m} \sigma_{a_{1}} \sqrt{2\left(1-\rho_{a_{1} a_{2}}^{2}\right)}\right)\right]^{\left(1-d_{i t}\right)}\right. \\
& \left.\times \Phi\left(\frac{A_{i t}+a_{m} \sigma_{a_{1}} \sqrt{2\left(1-\rho_{a_{1} a_{2}}^{2}\right)}+\frac{\rho_{u \epsilon}}{\sigma_{\epsilon}}\left(y_{i t}-B_{i t}-a_{p} \sigma_{a_{2}} \sqrt{2\left(1-\rho_{a_{1} a_{2}}^{2}\right)}\right)}{\sqrt{1-\rho_{u \epsilon}^{2}}}\right)^{d_{i t}}\right\},
\end{aligned}
$$

where $w_{m}, w_{p}, a_{m}$ and $a_{p}$ are respectively the weights and abscissas of the first- and second-stage Gauss-Hermite integration with $M$ and $P$ being the first- and second-stage total number of integration points. ${ }^{7}$ The same number of integration points $(P=M)$ is used in this study, although $P$ need not be equal to $M$. Equations (1) and (2) are correlated through the individual effects $\left(\rho_{a_{1} a_{2}} \neq 0\right)$ and the idiosyncratic errors $\left(\rho_{u \epsilon} \neq 0\right)$, and the "total" correlation between the two equations is calculated as

$$
\rho_{t o t}=\frac{\rho_{a_{1} a_{2}} \sigma_{a_{1}} \sigma_{a_{2}}+\rho_{u \epsilon} \sigma_{\epsilon}}{\sqrt{\left(\sigma_{a_{1}}^{2}+1\right)\left(\sigma_{a_{2}}^{2}+\sigma_{\epsilon}^{2}\right)}}
$$

\section{Data}

To implement the models, we use the same data as in Raymond et al. (2006) collected by the Centraal Bureau voor de Statistiek (CBS). They stem from three waves of the Dutch Community Innovation Survey, CIS 2 (1994-1996), CIS 2.5 (1996-1998) and CIS 3 (1998-2000), merged with data from the Production Survey (PS). Only enterprises in Dutch manufacturing (SBI 15-37) are included in the analysis. ${ }^{8}$ The population of interest consists of enterprises with at least ten employees and positive sales at the end of the period covered by the innovation survey. We consider enterprises that existed in

\footnotetext{
${ }^{7}$ Details on the calculation of the double integral can be found in Raymond et al. (2005).

${ }^{8} \mathrm{SBI}$ stands for the Dutch standard industrial classification and gives the enterprise economic activity.
} 
1994, survived until 2000 and took part in the three innovation surveys, resulting in a balanced panel of 861 enterprises.

Descriptive statistics and the definition of the variables are shown in Table 2. The dependent variable in equation (1) is binary indicating whether enterprise $i$ is a TPP innovator. $71 \%$ of such enterprises exist in our panel. Besides being a past TPP innovator, the probability of being a current TPP innovator is explained by lagged size and relative size, and industry dummies (according to SBI) that capture technological opportunities, the measurements of which are available for both TPP and non-TPP innovators. The dependent variable in equation (2) is the ratio of sales from new or improved products (innovative sales) over total sales. This variable is logit-transformed in order to make it lie within the set of real numbers. ${ }^{9}$ The average share of innovative sales is rather small $(29 \%)$ in our panel. Besides lagged size, the current share of innovative sales is explained by lagged dummy variables capturing demand pull, proximity to science, innovation cooperation, non-R\&D performers, continuous R\&D performers, subsidies, and lagged R\&D intensity. The characteristics of TPP innovators and R\&D performers are as follows. Product-oriented innovation objectives are deemed important to $64 \%$ of TPP innovators, only $21 \%$ of them use innovation sources from public or private institutions (e.g. universities). ${ }^{10}$ About $35 \%$ of TPP innovators have some kind of cooperation, $58 \%$ receive at least one subsidy and $80 \%$ are R\&D performers who spend on average $5 \%$ of their total sales in R\&D, and of which $75 \%$ perform R\&D continuously.

As mentioned earlier, most of the variables are qualitative and show little variation

\footnotetext{
${ }^{9}$ The share of innovative sales takes on the values 0 for process-only innovators, and 1 for innovators that are newly established. They are replaced respectively by 0.0001 and 0.9999 in the logit transformation.

${ }^{10}$ In the CIS questionnaire, an enterprise is asked about the importance of the objectives of innovation, 'open-up new markets', 'extend product range' and 'replace products phased out', on the basis of a 0-3 Likert scale. A dummy variable proxying demand pull equals one for an enterprise if at least one of the above objectives of innovation is given the highest mark (i.e. very important), and zero otherwise. Proximity to science is proxied by a dummy variable constructed from innovation indicators stating the importance of the sources of innovation from public or private institutions. This proxy takes on the value one if at least one of these institutions are deemed to be important or very important to an enterprise (i.e. at least one of the sources of innovation stemming from public or private institutions is given the values 2 or 3 ), and zero otherwise.
} 
over time. The few continuous variables typically vary more "between" enterprises than "within" enterprises over time. This is in part due to the rather small number of time periods $(T=3)$ of the panel.

Table 3 reports transition probabilities for innovation activities. $63 \%$ of non-TPP innovators and $78 \%$ of TPP innovators in CIS 2 remain in their initial state in CIS 3. The same holds for the two sub-periods. As regards innovation intensity, $73 \%$ of the innovators with below average intensity in CIS 2 remain below average in CIS 2.5 and CIS 3, and about $70 \%$ are always above average. The general pattern in the figures of Table 3 is that innovation activities are persistent which may occur, as mentioned earlier, for two reasons namely true and spurious state dependence. In order to distinguish the former from the latter, we estimate eqs. (1) and (2) using the estimation technique described in Section 4. We now present the estimation results.

\section{Results}

By simultaneous estimation of equations (1) and (2) an answer is sought to the two research questions taken jointly. As product-life cycle and R\&D intensity vary across industries, the persistence of innovation and $R \& D$ intensity may be expected to be industry-specific (Malerba and Orsenigo, 1999; Cefis and Orsenigo, 2001). In first instance, a test was performed on the equality of the industry persistence parameters (coefficients of the lagged dependent variables) and industry intercepts. The joint null hypothesis that the industry persistence parameters and the industry intercepts are equal could not be rejected. In Table 4 the results are presented of the model in which the industry persistence parameters and industry intercepts are restricted to be equal. In order to show the importance of accounting for individual effects and handling the initial conditions problem, we present the estimation results of the dynamic type 2 tobit model without accounting for individual effects in the first pair of column in Table 4, and 
those of the same model in which individual effects have been taken into account but the initial conditions have been assumed exogenous in the second pair of columns. These results are to be contrasted with the estimates in the third pair of columns resulting from estimation of the dynamic type 2 tobit model in which both individual effects have been taken into account and the initial conditions have been treated as endogenous. The estimation results on the persistence of innovation, i.e. the estimates of the parameters in equation (1), are presented in the upper part of Table 4 and discussed in subsection 6.1. The estimation results on the dynamics of innovation output, i.e. the estimates of the parameters in equation (2), are presented in the middle part of Table 4 and discussed in subsection 6.2. Finally, the outcomes of some sensitivity analyses are reported on in subsection 6.3 .

\subsection{The persistence of innovation}

No individual effects and individual effects with exogenous initial conditions

The estimation results of the dynamic type 2 tobit model assuming the absence of individual effects and, alternatively, accounting for individual effects and assuming the initial conditions to be exogenous are very similar. ${ }^{11}$ The persistence parameter is positive and highly significant and lagged size affects positively and significantly the probability to innovate. As mentioned earlier, the persistence of innovation may be spurious. The existence of true persistence in innovation may be ascertained by verifying that, after accounting for individual effects and properly handling the initial conditions problem, the effect of the lagged dependent variable is, economically and statistically, relevant.

\section{Individual effects and endogenous initial conditions}

\footnotetext{
${ }^{11}$ Exogenous initial conditions imply that being successful in achieving TPP innovations at the initial period does not affect the probability to innovate later on.
} 
Once the two typical problems of individual effects and initial conditions are properly handled, the hypothesis that the persistence parameter, i.e. the coefficient of the lagged dependent variable, is equal to zero can no longer be rejected. This result contrasts with that of Duguet and Monjon (2002) who find strong persistence in achieving TPP innovations in French manufacturing. However, they do not account for individual effects, and their finding of persistence may well be due to spurious state dependence. Furthermore, lagged size positively and significantly affects the probability to innovate.

\subsection{The dynamics of innovation output}

No individual effects and individual effects with exogenous initial conditions

The estimates of the parameters of equation (2) are also similar in the dynamic type 2 tobit model without individual effects and in the model with individual effects and exogenous initial conditions. The persistence parameter is positive and highly significant. Furthermore, past R\&D intensity, size and demand pull positively affect the current share of innovative sales and, ceteris paribus, past non-R\&D performers are less successful than past $\mathrm{R} \& \mathrm{D}$ performers.

\section{Individual effects and endogenous initial conditions}

The results suggest that, even after accounting for individual effects and handling the initial conditions problem, the persistence parameter remains significant at $1 \%$ level of significance, suggesting that past innovation output generates in part current innovation output. As for the other regressors, the results mentioned above remain valid.

Both the model that assumes the absence of individual effects and the one that accounts for individual effects but assumes exogenous initial conditions are rejected using a likelihood ratio test at $1 \%$ level of significance. Hence, the full model is the preferred one where equations (1) and (2) are jointly estimated allowing for a correlation between 
the processes governing the introduction of TPP innovations and the generation of innovative sales. Both cross-equation individual effects and cross-equation idiosyncratic parts are found to be correlated and the "total" correlation (eq. (13)) between the two equations is calculated ex post to be 0.162 .

\subsection{Robustness analysis}

When no correlation is assumed between the decision to be a TPP innovator and the share of innovative sales, consistent and efficient estimators of the parameters of the type 2 tobit model may be obtained by separately estimating equations (1) and (2). We use estimation techniques by Heckman (1981b) and Wooldridge (2005) (eq. (1)) and Anderson and Hsiao (1981; 1982) (eq. (2)). The estimation results from separate estimations reveal the same pattern: similar to the results in Table 4, persistence in achieving TPP innovations vanishes when individual effects and the initial conditions are dealt with, while inertia shows up in the share of innovative sales. Hence, the lack of persistence in achieving TPP innovations is a rather robust result.

Also the sensitivity of the model to using R\&D input rather than output measures has been investigated. The dynamic type 2 tobit has been estimated using the incidence of engaging in R\&D activities rather than that of being a TPP innovator as dependent variable in equation (1) and using $R \& D$ intensity rather than the share of innovative sales as dependent variable in equation (2). The results of this analysis show the same pattern as that of Table 4, with the exception of the probit persistence parameter that remains significant also in the preferred model accounting for individual effects and the endogeneity of the initial conditions. More specifically, the magnitude of the persistence parameters in both equations lessens when accounting for individual effects and assuming endogenous initial conditions. In this analysis the full model is also shown to be the preferred one: the restrictions imposed in the model without individual effects on the one hand, and those imposed in the model with individual effects and exogenous initial 
conditions, on the other hand, are - as in Table 4 - rejected using a likelihood ratio test. ${ }^{12}$

\section{Conclusion}

This study gives first insights into the persistence of innovation and the dynamics of innovation output in Dutch manufacturing using three waves of the CIS. We answer the questions jointly by estimating a dynamic type 2 tobit and find that there is no evidence of persistence in achieving TPP innovations, while past shares of innovative sales condition, albeit to a small extent, current shares of innovative sales. The lack of persistence of innovation contrasts with results by Duguet and Monjon (2002) who find evidence of strong persistence in innovation in French manufacturing. Once the individual effects and the initial conditions are allowed for, they seem to take over the role of persistence. This phenomenon is even more plausible when the panel is short because, the shorter the panel the higher the correlation between the initial conditions $\left(d_{i 0}\right)$ and the lagged dependent variable $\left(d_{i, t-1}\right)$. The fact that the same phenomenon does not take place in the regression equation (eq. (2)) indicates that the lack of persistence found cannot be attributed only to the shortness of the panel. This issue remains a topic of future research. The results on the sensitivity of the model to using R\&D input rather than output measures indicate that there is evidence of persistence in engaging in R\&D activities and in the share of $R \& D$ expenditures in total sales. The former result is in accordance with Máñez Castillejo et al. (2004) who find evidence of persistence by Spanish manufacturing firms in engaging in R\&D activities, and Peters (2005) who finds persistence by German manufacturing and services firms in engaging in innovation activities. Our results suggest that there is evidence of true persistence of innovation when considered on the input side and spurious persistence when taken on the output side. The idea is that persistent R\&D performers may not be guaranteed to persistently

\footnotetext{
${ }^{12}$ The tabulated results of the robustness analysis can be obtained upon request.
} 
achieve TPP innovations.

The main caveat of this study is the data we use to implement the model. First, the panel is rather short $(T=3)$ which may explain in part the lack of true persistence in achieving TPP innovations. Secondly, there is one-year overlap between two consecutive waves of the Dutch CIS. Hence, to the extent that respondents answer this survey consistently, the overlap would tend to bias the results towards persistence in being a TPP innovator. As no evidence of persistence is found in the preferred model, it may be concluded that the effect of the overlapping year is not important.

\section{References}

Abramovitz, Milton, and Irene Stegun (1964) Handbook of Mathematical Functions with Formulas, Graphs, and Mathematical Tables (Washington, D.C..: National Bureau of Standards Applied Mathematics, US Government Printing Office).

Aghion, Philippe, and Peter Howitt (1992) "A Model of Growth Through Creative Destruction," Econometrica 60, 323-351.

Ahn, Seung C., and Peter Schmidt (1995) "Efficient Estimation of Models for Dynamic Panel Data," Journal of Econometrics 68, 5-27.

Amemiya, Takeshi (1984) "Tobit Models: A Survey," Journal of Econometrics 24, 3-62.

Anderson, Theodore W., and Cheng Hsiao (1981) "Estimation of Dynamic Models with Error Components," Journal of the American Statistical Association 76, 598-606.

_ (1982) "Formulation and Estimation of Dynamic Models Using Panel Data," Journal of Econometrics 18, 47-82.

Brouwer, Eric, and Alfred H. Kleinknecht (1996) "Determinants of Innovation: A Micro Econometric Analysis of Three Alternative Innovative Output Indicators," in 
Alfred H. Kleinknecht (Ed.), Determinants of Innovation: The Message from New Indicators (London: Macmillan).

Cabagnols, Alexandre, Claudine Gay, and Christian Le Bas (1999) "'How Persistently do Firms Innovate?" An Evolutionary View. An Empirical Application of Duration Models." CNRS Collection Les Cahiers de l'Innovation no. 00001.

Cefis, Elena (2003a) "Is there Persistence in Innovative Activities?," International Journal of Industrial Organization 21, 489-515.

_ (2003b) "Persistence in Innovation and Profitability," Rivista Internazionale di Scienze Sociali, 1, 19-37.

Cefis, Elena, and Luigi Orsenigo (2001) "The Persistence of Innovative Activities A Cross-Countries and Cross-Sectors Comparative Analysis," Research Policy 30, 1139-1158.

Cefis, Elena, and Matteo Ciccarelli (2005) "Profit Differentials and Innovation," Economics of Innovation and New Technology 14, 43-61.

Crépon, Bruno, and Emmanuel Duguet (1997) "Estimating the Innovation Function from Patent Numbers: GMM on Count Panel Data," Journal of Applied Econometrics $12,243-263$.

Crépon, Bruno, Emmanuel Duguet, and Jacques Mairesse (1998) "Research, Innovation, and Productivity: An Econometric Analysis at the Firms Level." NBER Working Paper no. 6696.

Duguet, Emmanuel, and Stéphanie Monjon (2002) "Creative Destruction and the Innovative Core: Is Innovation Persistent at the Firm Level?" UCL Discussion Paper $02-07$. 
Geroski, Paul A. (1989) "Entry, Innovation and Productivity Growth," The Review of Economics and Statistics 71, 572-578.

Geroski, Paul A., John van Reenen, and Chris F. Walters (1997) "How Persistently do Firms Innovate?," Research Policy 26, 33-48.

Griliches, Zvi (1990) "Patent Statistics as Economic Indicators: A Survey," Journal of Economic Literature 28, 1661-1707.

Heckman, James J. (1981a) "Heterogeneity and State Dependence," in S Rosen (Ed.), Studies in Labor Markets (University of Chicago Press) pp. 91-139.

_ (1981b) "The Incidental Parameters Problem and the Problem of Initial Conditions in Estimating a Discrete Time-Discrete Data Stochastic Process," in Charles F. Manski, and Daniel McFadden (Eds.), Structural Analysis of Discrete Data with Econometric Applications (Cambridge, MA: MIT Press) pp. 179-195.

(1981c) "Statistical Models for Discrete Panel Data," in Charles F. Manski, and Daniel McFadden (Eds.), Structural Analysis of Discrete Data with Econometric Applications (Cambridge, MA: MIT Press) pp. 114-178.

Honoré, Bo E., and Ekaterini Kyriazidou (2000) "Panel Data Discrete Choice Models with Lagged Dependent Variables," Econometrica 69, 839-874.

Janz, Norbert, Hans Loöf, and Bettina Peters (2004) "Firm Level Innovation and Productivity: Is there a Common Story Across Countries," Problems and Perspectives in Management.

Klomp, Luuk, and George van Leeuwen (2001) "Linking Innovation and Firm Performance: A New Approach," International Journal of the Economics of Business $8,343-364$. 
Kyriazidou, Ekaterini (2001) "Estimation of Dynamic Panel Data Sample Selection Models," Reviews of Economic Studies 68, 543-572.

Lööf, Hans, and Almas Heshmati (2002a) "Knowledge Capital and Performance Heterogeneity: A Firm-Level Innovation Study," International Journal of Production Economics 76, 61-85.

_ (2002b) "On the Relationship between Innovation and Performance: A Sensitivity Analysis." SSE/EFI Working Paper Series in Economics and Finance no. 446.

Máñez Castillejo, Juan A., María E. Rochina Barrachina, Amparo Sanchis Llopis, and Juan A. Sanchis Llopis (2004) "A Dynamic Approach to the Decision to Invest in R\&D: The Role of Sunk Costs." mimeo.

Mairesse, Jacques, and Pierre Mohnen (2001) "To Be or Not To Be Innovative: An Exercise in Measurement," STI Review Special Issue on New Science and Technology Indicators $27,103-129$.

Malerba, Franco, and Luigi Orsenigo (1999) "Technological Entry, Exit and Survival: an Empirical Analysis of Patent Data," Research Policy 28, 643-660.

Peters, Bettina (2005) "Persistence of Innovation: Stylised Facts and Panel Data Evidence." ZEW Discussion Paper, No. 05-81.

Pianta, Mario (2004) "Innovation and Employment," in Jan Fagerberg, David C Mowery, and Richard R Nelson (Eds.), The Oxford Handbook of Innovation (Oxford University Press) chapter 21.

Raymond, Wladimir, Pierre Mohnen, Franz Palm, and Sybrand Schim van der Loeff (2005) "Maximum Likelihood Estimation of Panel Data Sample Selection Models." mimeo. 
_ (2006) "A Classification of Dutch Manufacturing Based on a Model of Innovation," De Economist 154, 1-21.

Roberts, Peter W. (2001) "Innovation and Firm-Level Persistent Profitability: A Schumpeterian Framework," Managerial and Decision Economics 22, 239-250.

Romer, Paul M. (1990) "Endogenous Technical Change," The Journal of Political Economy $98, \mathrm{~S} 71-\mathrm{S} 102$.

van Leeuwen, George (2002) "Linking Innovation to Productivity Growth Using two Waves of the Community Innovation Survey." OECD Science, Technology and Industry Working Papers, 2002/8, OECD Publishing.

Wooldridge, Jeffrey M. (2005) "Simple Solutions to the Initial Conditions Problem in Dynamic Nonlinear Panel Data Models with Unobserved Heterogeneity," Journal of Applied Econometrics 20, 39-54. 
Table 1: Empirical studies on the persistence of innovation

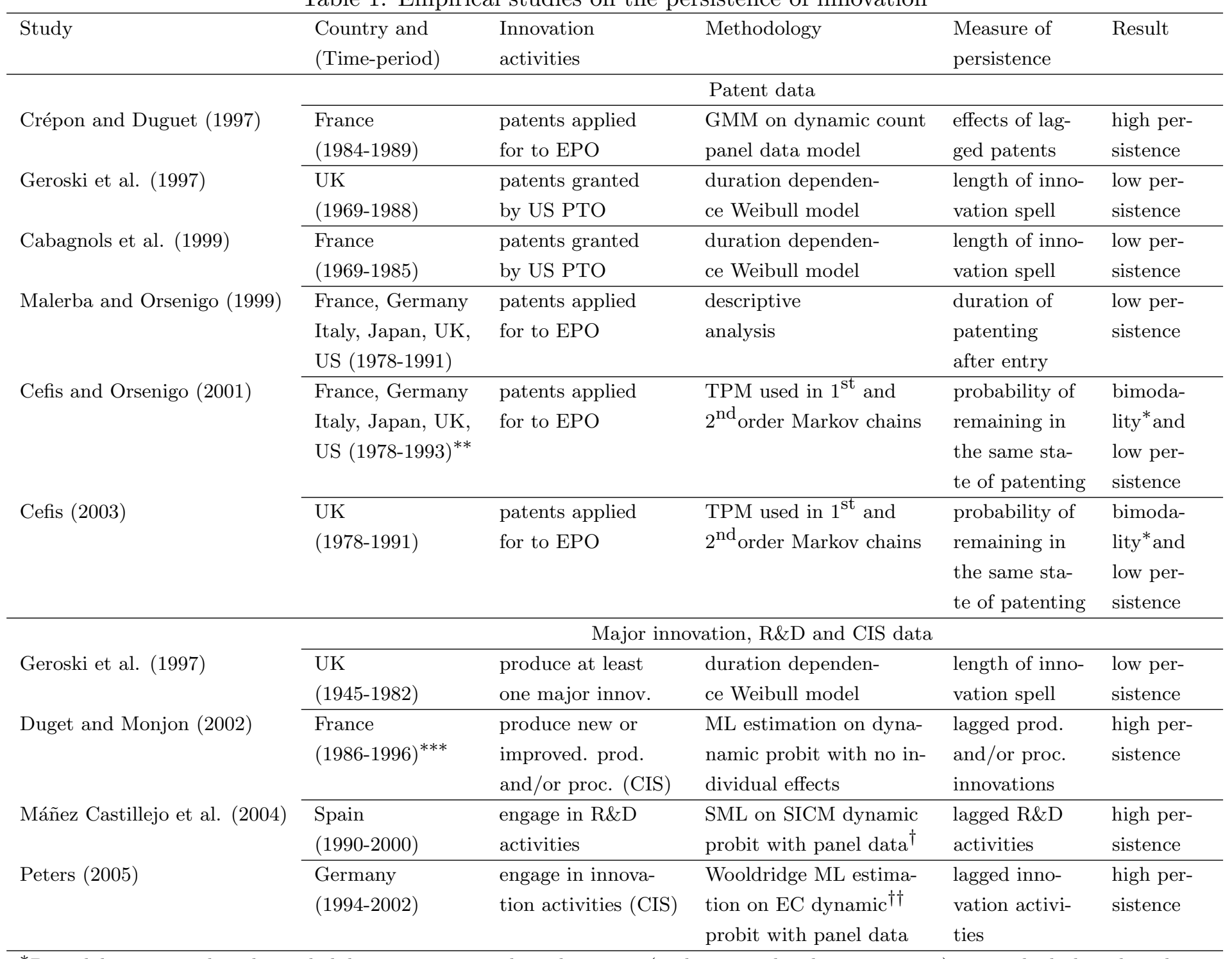

* Bimodality means that the probability to remain in the polar states (with zero and at least 6 patents) is very high, but the other probabilities are low, leading to low persistence in general. ${ }^{* *}$ The period is 1978-1991 for the UK; TPM means transition probability matrix. ${ }^{* * *} 1993$ information is missing. ${ }^{\dagger}$ SML and SICM mean simulated maximum likelihood and stationary intertemporal covariance matrix respectively. ${ }^{\dagger \dagger} \mathrm{EC}$ means error-components. 
Table 2: Descriptive statistics

\begin{tabular}{|c|c|c|c|c|c|}
\hline Variable & Description & Mean & $\begin{array}{l}\text { Overall } \\
\text { Std. Dev. }\end{array}$ & $\begin{array}{l}\text { Between } \\
\text { Std. Dev. }\end{array}$ & $\begin{array}{l}\text { Within } \\
\text { Std. Dev. }\end{array}$ \\
\hline & \multicolumn{5}{|c|}{ Dependent variables } \\
\hline TPP innovator & $\begin{array}{l}1 \text { if product and/or } \\
\text { process innovator }\end{array}$ & 0.714 & 0.452 & 0.350 & 0.287 \\
\hline $\begin{array}{l}\text { Intensity of } \\
\text { innnovation* }\end{array}$ & $\begin{array}{l}\text { innovative sales/total sales } \\
\text { (for TPP innovators) }\end{array}$ & 0.290 & 0.258 & 0.218 & 0.147 \\
\hline & \multicolumn{5}{|c|}{ Regressors } \\
\hline Demand pull & $\begin{array}{l}1 \text { if product-oriented innova- } \\
\text { tion objectives are very } \\
\text { important (for TPP innovators) }\end{array}$ & 0.640 & 0.480 & 0.370 & 0.337 \\
\hline $\begin{array}{l}\text { Proximity } \\
\text { to science }\end{array}$ & $\begin{array}{l}1 \text { if innovation sources are } \\
\text { from universities or other } \\
\text { institutes (for TPP innovators) }\end{array}$ & 0.213 & 0.410 & 0.298 & 0.271 \\
\hline $\begin{array}{l}\text { Innovation } \\
\text { cooperation }\end{array}$ & $\begin{array}{l}1 \text { if there is any type of coope- } \\
\text { ration (for TPP innovators) }\end{array}$ & 0.349 & 0.477 & 0.379 & 0.293 \\
\hline $\begin{array}{l}\text { Non-R\&D } \\
\text { performers }\end{array}$ & $\begin{array}{l}1 \text { if not performing R\&D } \\
\text { (for TPP innovators) }\end{array}$ & 0.196 & 0.397 & 0.380 & 0.214 \\
\hline $\begin{array}{l}\text { Continuous R\&D } \\
\text { performers }\end{array}$ & $\begin{array}{l}1 \text { if performing continuous } \\
R \& D \text { (for R\&D performers) }\end{array}$ & 0.754 & 0.431 & 0.399 & 0.247 \\
\hline Subsidies & $\begin{array}{l}1 \text { if being subsidized at least } \\
\text { once (for TPP innovators) }\end{array}$ & 0.577 & 0.494 & 0.424 & 0.284 \\
\hline R\&D intensity ${ }^{* *}$ & $\begin{array}{l}\text { R\&D expenditures/total sales } \\
\text { (for R\&D performers) }\end{array}$ & 0.046 & 0.078 & 0.064 & 0.037 \\
\hline $\operatorname{Size}^{\dagger}$ & number of employees & 209.962 & 539.248 & 534.722 & 71.292 \\
\hline Relative size ${ }^{\dagger \dagger}$ & total sales/sales of industry & 0.006 & 0.020 & 0.020 & 0.004 \\
\hline \# of observations & \multicolumn{5}{|c|}{2583} \\
\hline
\end{tabular}


Table 3: Transition probability: persistence in innovation activities

\begin{tabular}{|c|c|c|c|c|c|c|c|}
\hline \multirow[b]{2}{*}{ CIS 2} & \multicolumn{3}{|c|}{ CIS 3} & \multirow[b]{2}{*}{ CIS 2.5} & \multicolumn{3}{|c|}{ CIS 3} \\
\hline & Non-TPP (\%) & TPP (\%) & Total & & Non-TPP (\%) & TPP (\%) & Total \\
\hline Non-TPP & 63.16 & 36.84 & 228 & Non-TPP & 64.50 & 35.50 & 231 \\
\hline TPP & 21.64 & 78.36 & 633 & TPP & 20.95 & 79.05 & 630 \\
\hline \multirow[t]{2}{*}{ Total } & 281 & 580 & 861 & Total & 281 & 580 & 861 \\
\hline & \multicolumn{3}{|c|}{ Innov. intens. in CIS 3} & & \multicolumn{3}{|c|}{ Innov. intens. in CIS 3} \\
\hline CIS 2 & Below avg. (\%) & Above avg. (\%) & Total & CIS 2.5 & Below avg. (\%) & Above avg. (\%) & Total \\
\hline Below avg. & 73.81 & 26.19 & 565 & Below avg. & 73.01 & 26.99 & 552 \\
\hline Above avg. & 28.38 & 71.62 & 296 & Above avg. & 31.72 & 68.28 & 309 \\
\hline Total & 501 & 360 & 861 & Total & 501 & 360 & 861 \\
\hline
\end{tabular}


Table 4: Dynamic type 2 tobit estimates: Innovation output

\begin{tabular}{|c|c|c|c|c|c|c|}
\hline Variable & Coefficient & (Std. Err.) & Coefficient & (Std. Err.) & Coefficient & (Std. Err.) \\
\hline \multicolumn{3}{|l|}{ Estimation } & \multicolumn{4}{|c|}{ Unobserved individual effects } \\
\hline method & \multicolumn{2}{|c|}{$\begin{array}{l}\text { No unobserved } \\
\text { individual effects }\end{array}$} & \multicolumn{2}{|c|}{$\begin{array}{l}\text { Exogenous initial } \\
\text { conditions }\end{array}$} & \multicolumn{2}{|c|}{$\begin{array}{c}\text { Endogenous initial } \\
\text { conditions }\end{array}$} \\
\hline \multicolumn{7}{|c|}{ Current TPP innovation $\left(d_{i t}\right)$} \\
\hline Past TPP innovation $\left(d_{i, t-1}\right)$ & $0.955^{* *}$ & $(0.142)$ & $0.928^{* *}$ & $(0.150)$ & 0.294 & $(0.187)$ \\
\hline Size & $0.164^{* *}$ & $(0.061)$ & $0.171^{* *}$ & $(0.065)$ & $0.197^{* *}$ & $(0.074)$ \\
\hline Relative size & 0.055 & $(0.042)$ & 0.055 & $(0.044)$ & 0.059 & $(0.051)$ \\
\hline Intercept & -0.534 & $(0.532)$ & -0.522 & $(0.558)$ & -0.836 & $(0.643)$ \\
\hline \multicolumn{7}{|c|}{ Current share of innovative sales $\left(y_{i t}\right.$ in logit) } \\
\hline Past share of innovative sales $\left(y_{i, t-1}\right)$ & $0.270^{* *}$ & $(0.027)$ & $0.246^{* *}$ & $(0.033)$ & $0.110^{* *}$ & $(0.042)$ \\
\hline Size (in log) & $0.472^{* *}$ & $(0.129)$ & $0.487^{* *}$ & $(0.133)$ & $0.522^{* *}$ & $(0.138)$ \\
\hline $\mathrm{R} \& \mathrm{D}$ intensity (in $\log$ ) & $0.607^{* *}$ & $(0.098)$ & $0.616^{* *}$ & $(0.100)$ & $0.631^{* *}$ & $(0.101)$ \\
\hline Non-R\&D performers & $-3.532^{* *}$ & $(0.644)$ & $-3.544^{* *}$ & $(0.648)$ & $-3.537^{* *}$ & $(0.652)$ \\
\hline Continuous R\&D performers & -0.456 & $(0.330)$ & -0.491 & $(0.332)$ & -0.471 & $(0.332)$ \\
\hline Demand pull & $0.611^{*}$ & $(0.245)$ & $0.616^{*}$ & $(0.245)$ & $0.582^{*}$ & $(0.244)$ \\
\hline Proximity to science & 0.211 & $(0.251)$ & 0.187 & $(0.253)$ & -0.314 & $(0.286)$ \\
\hline Cooperation in innovation & -0.335 & $(0.283)$ & -0.356 & $(0.285)$ & 0.114 & $(0.255)$ \\
\hline Subsidies & 0.215 & $(0.275)$ & 0.260 & $(0.279)$ & 0.282 & $(0.281)$ \\
\hline Intercept & -1.979 & $(0.807)$ & $-2.065^{*}$ & $(0.825)$ & $-2.069^{*}$ & $(0.846)$ \\
\hline \multicolumn{7}{|c|}{ Extra parameters } \\
\hline Initial share of innovative sales $\left(y_{i 0}\right)$ & - & - & - & - & $0.156^{* *}$ & $(0.037)$ \\
\hline Initial TPP innovation $\left(d_{i 0}\right)$ & - & - & - & - & $1.025^{* *}$ & $(0.164)$ \\
\hline$\sigma_{a_{1}}$ & - & - & 0.267 & $(0.222)$ & $0.545^{* *}$ & $(0.180)$ \\
\hline$\sigma_{a_{2}}$ & - & - & $1.096^{* *}$ & $(0.414)$ & $1.736^{* *}$ & $(0.279)$ \\
\hline$\sigma_{\epsilon}$ & $1.446^{* *}$ & $(0.027)$ & $4.102^{* *}$ & $(0.151)$ & $3.862^{* *}$ & $(0.136)$ \\
\hline$\rho_{a_{1} a_{2}}$ & - & - & $0.491^{*}$ & $(0.168)$ & $0.425^{* *}$ & $(0.135)$ \\
\hline$\rho_{u \epsilon}$ & $0.783^{* *}$ & $(0.028)$ & $0.803^{* *}$ & $(0.037)$ & $0.869^{* *}$ & $(0.061)$ \\
\hline
\end{tabular}

Number of observations

1334

Log-likelihood $\quad-3511.873$

$-3511.024$

$-3477.945$

Significance levels : $\quad \dagger: 10 \% \quad *: 5 \% \quad * *: 1 \%$ 